Comparative experimental study of $x$-ray absorption spectroscopy and electron energy loss spectroscopy on passivated U surfaces

A. Nelson, W. Moberlychan, R. A. Bliss, W. Siekhaus, T. Felter, J. Denliner

December 13, 2006

2006 MRS Fall Meeting

Boston, MA, United States

November 27, 2006 through December 1, 2006 
This document was prepared as an account of work sponsored by an agency of the United States Government. Neither the United States Government nor the University of California nor any of their employees, makes any warranty, express or implied, or assumes any legal liability or responsibility for the accuracy, completeness, or usefulness of any information, apparatus, product, or process disclosed, or represents that its use would not infringe privately owned rights. Reference herein to any specific commercial product, process, or service by trade name, trademark, manufacturer, or otherwise, does not necessarily constitute or imply its endorsement, recommendation, or favoring by the United States Government or the University of California. The views and opinions of authors expressed herein do not necessarily state or reflect those of the United States Government or the University of California, and shall not be used for advertising or product endorsement purposes. 


\title{
Comparative experimental study of x-ray absorption spectroscopy and electron energy loss spectroscopy on passivated $U$ surfaces
}

\author{
A.J. Nelson ${ }^{1}$, W.J. Moberlychan ${ }^{1}$, R.A. Bliss ${ }^{1}$, W. Siekhaus ${ }^{1}$, T.E. Felter ${ }^{1}$, and J. Denlinger ${ }^{2}$ \\ ${ }^{1}$ Lawrence Livermore National Laboratory, Livermore, CA 94551 \\ ${ }^{2}$ Lawrence Berkeley National Laboratory, Berkeley, CA 94720
}

\begin{abstract}
X-ray absorption spectroscopy and electron energy loss spectroscopy are complementary analytical techniques on energy and spatial resolution. These techniques are based on the same fundamental physical process of core excitation with either an incident photon or incident electron. In the proper experimental configuration the electron and photon inelastic scattering amplitudes are comparable and thus the x-ray and electron absorption edges look identical. We have applied these two complementary analytical techniques to investigate the electronic structure of $\mathrm{C}$ ion implanted $\mathrm{U}$. Implantation of $\mathrm{C}^{+}$ions into $\mathrm{U}^{238}$ has been shown to produce a physically and chemically modified surface layer that passivates the surface preventing further air oxidation and corrosion. Comparison of the resultant spectra reveal that transitions between the initial state and a series of final states yield numerous strong features at the absorption edge that can provide structural information and information on the local chemical environment, including the character of the U $5 f$ state.
\end{abstract}

\section{INTRODUCTION}

Emerging science involving small structures, structure property relations controlled at the nanoscale, and chemical research at the molecular scale require small probe characterization capabilities in the sub-micron to near atomic level coupled with elemental and chemical specificity. In addition, knowledge of the surface reactions of uranium metal on the nanoscale with various environmental and atmospheric agents, and the subsequent degradation processes, are vitally important in $21^{\text {st }}$ century nuclear technology. Inelastic electron scattering techniques have the potential for elucidating these processes.

Synchrotron radiation based $\mathrm{x}$-ray absorption spectroscopy (XAS) is a highly developed capability for characterizing the electronic structure of materials. However, this technique has had limited spatial resolution while technological advancements now require nanoscale spatial resolution. Electron energy loss spectroscopy (EELS) has developed in parallel but has the advantage of atomic resolution when combined with transmission electron microscopy (TEM).

XAS and EELS are complementary analytical techniques on energy and spatial resolution. These techniques are based on the same fundamental physical process of core excitation with either an incident photon or incident electron. XAS has only dipole allowed transitions, but both dipole and non-dipole transitions are observed with EELS. However, for small momentum transfer or for small scattering angles, electron and photon inelastic scattering amplitudes are comparable and thus the x-ray and electron absorption edges look identical. [1-4]

We have applied these two complementary analytical techniques to investigate the electronic structure of $\mathrm{C}$ ion implanted $\mathrm{U}$. Implantation of $\mathrm{C}^{+}$ions into $\mathrm{U}^{238}$ has been shown to produce a physically and chemically modified surface layer that passivates the surface preventing further air oxidation and corrosion. [5] Core-level photoelectron spectroscopy in 
combination with time-of-flight secondary ion mass spectrometry (ToF-SIMS) depth profiling confirmed the surface chemistry and depth distribution of the U-carbide layer. [6]

This combination of XAS and EELS has been applied to the study of transition metal oxides [7] and superconductors [8]. The higher energy resolution of XAS was used to examine the electronic structure of a region of interest while EELS was used to examine the electronic structure of individual grains in the polycrystalline material. More recently these complementary techniques have been applied in the nanoscale regime to oxygen passivated Fe nanoparticles (NPs) [9] and rare earth oxide NPs. [10]

\section{EXPERIMENTAL}

Polycrystalline $U$ was prepared with a final mechanical polishing step using $0.5 \mathrm{um}$ diamond paste that provided a near mirror finish. Initial oxidation of the $U$ in laboratory air prior to introduction into the ion implanter vacuum chamber results in a $\leq 20 \mathrm{~nm}$ oxide. [11,12] Implantation of $33 \mathrm{keV} \mathrm{C}^{+}$ions into the polycrystalline $\mathrm{U}^{238}$ with a dose of $4.3 \mathrm{x} 10^{17} \mathrm{~cm}^{-2}$ produced a physically and chemically modified surface layer that prevents further air oxidation and corrosion. The TRIM calculated sputtering rates of the surface oxygen and surface uranium by the implanting carbon ions are $44 \%$ and $23 \%$, respectively. Note that the thin initial oxide layer $(\approx 20 \mathrm{~nm})$ was sputtered and modified during the ion irradiation. [6]

Uranium $5 d$ core-level XAS and EELS were performed on these C implanted samples. These techniques probe empty, or unfilled $5 f$ electronic states of uranium and provide information on the local chemical environment. The XAS measurements were performed on beamline 8.0.1 at the Advanced Light Source (ALS). Spatial resolution at this beamline is on the order of $10 \mu \mathrm{m}$. Energy resolution is also on the order of $0.15 \mathrm{eV}$. The EELS measurements were performed using a $300 \mathrm{kV}$ field emission gun transmission electron microscope (TEM) with a Gatan imaging filter (GIF). Recovery of the TEM thin sections from bulk material was accomplished using a dual beam focused ion beam (FIB) tool. The TEM samples were plasma cleaned with $\sim 80 \% \mathrm{Ar}+20 \% \mathrm{O}_{2}$ to remove $\mathrm{C}$ contamination prior to analysis. This plasma treatment attacked the $\mathrm{U}$, drastically corroding it. However, this nanometer-scale corrosion experiment shows the C-implanted zone judiciously resisted oxidation.

\section{RESULTS AND DISCUSSION}

The XAS technique probes empty or unfilled electronic states and provides information on the local chemical environment. Transitions between the initial state $\left(5 d^{10} 5 f^{\mathrm{N}}, \mathrm{N}=0,1,2,3\right.$ for $\mathrm{U}^{+6}, \mathrm{U}^{+5}, \mathrm{U}^{+4}, \mathrm{U}^{+3}$ respectively) and a series of final states $\left(5 d^{9} 5 f^{\mathrm{N}+1}\right)$ yields numerous strong features at the $\mathrm{U}$ O-edge that can provide structural information. For $5 d$ x-ray absorption, the dipole allowed transitions are $5 d \rightarrow 5 f$ and $5 d \rightarrow 6 p$, with transitions to the $5 f$ state dominant. Strong multiplet effects are observed in the $\mathrm{O}_{4,5} \mathrm{x}$-ray absorption thresholds due to the increase in orbital overlap between the core-hole and $5 f$ electrons, i.e. the $5 d-5 f$ exchange interaction is comparable to the $5 d^{9}$ spin-orbit interaction.

The $\mathrm{O}_{4,5} \mathrm{X}$-ray absorption spectrum of $\mathrm{C}^{+}$implanted $\mathrm{U}$ is presented in Figure 1 and shows four peaks denoted by A, B, C, D and E. Comparison with the $\mathrm{O}_{4,5}$ thresholds for $\alpha-\mathrm{U}$ metal, $\mathrm{UF}_{4}, \mathrm{UO}_{2}$ and $\mathrm{UO}_{3}$ help determine the character of the $5 f$ state. [13,14] Specifically, the pre-peak in our spectrum for $\mathrm{C}^{+}$implanted uranium has two distinct features $(\mathrm{A}, \mathrm{B})$ that are only seen in 


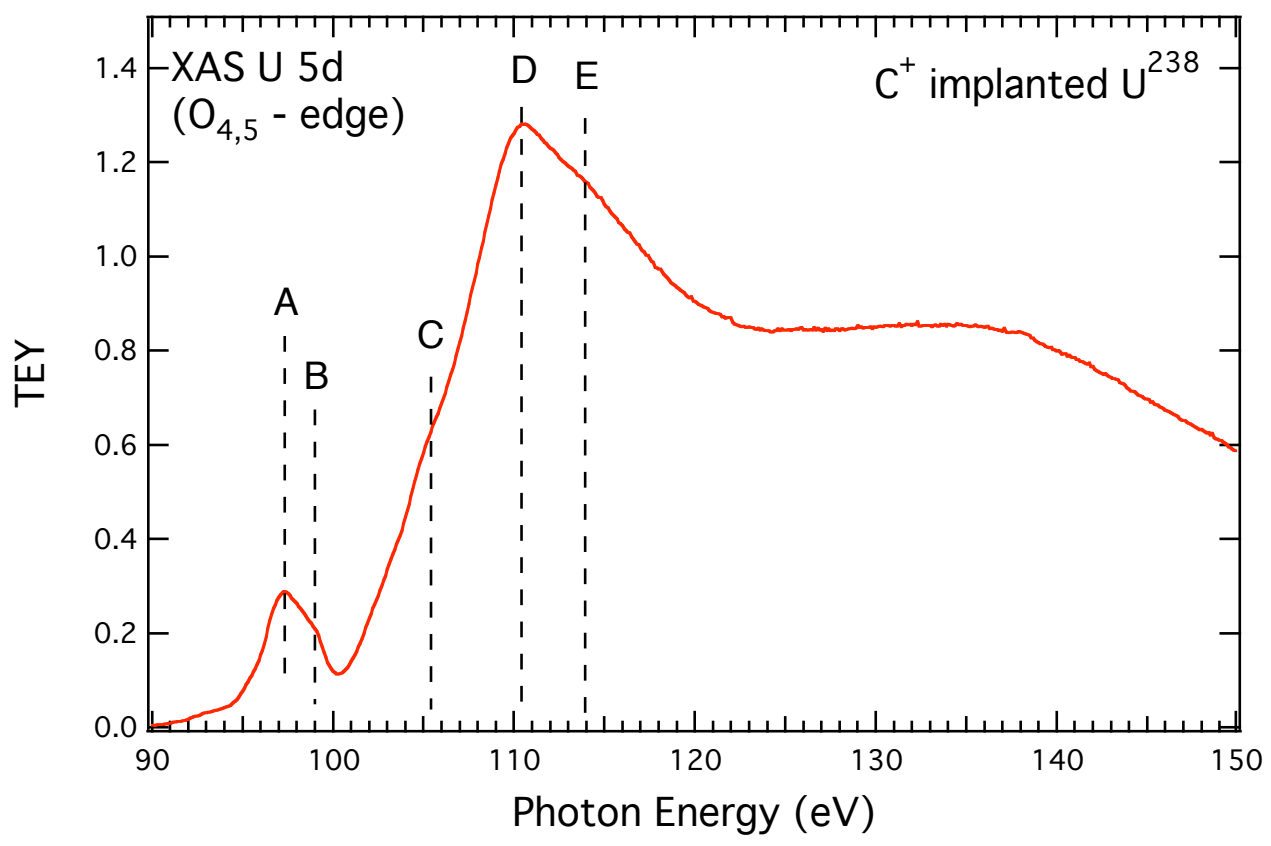

Figure 1. Uranium $\mathrm{O}_{4,5}$-edge photoabsorption spectrum for $\mathrm{C}^{+}$implanted polycrystalline $\mathrm{U}^{238}$.

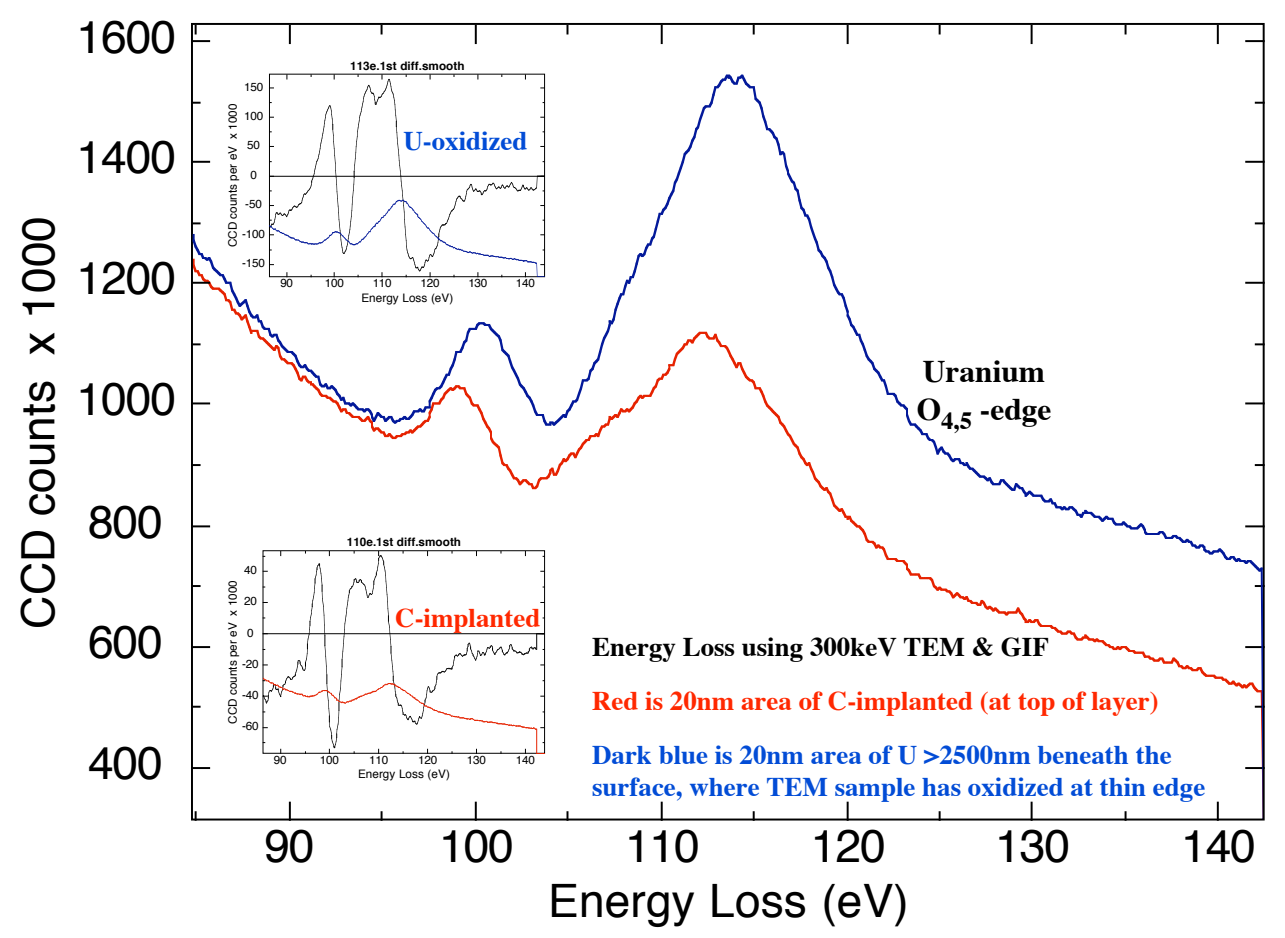

Figure 2. Comparison of Uranium $\mathrm{O}_{4,5}$-edge electron energy loss spectrum for $\mathrm{C}^{+}$implanted (red) and oxidized (blue) polycrystalline $\mathrm{U}^{238}$. The insets present the derivative of the spectra for comparison. 
the $\mathrm{O}_{4,5}$ spectra for $\mathrm{UF}_{4}$ and $\mathrm{UO}_{2}$. Similarly, feature $\mathrm{C}$ is also only observed in the $\mathrm{O}_{4,5}$ spectra for $\mathrm{UF}_{4}$ and $\mathrm{UO}_{2}$. These features represent $5 d-5 f$ multiplet excitations with a $5 d$ core hole final state. For metallic $\mathrm{U}$ systems, the $\mathrm{O}_{4,5}$ spectra are broad and there is a loss of multiplet features, which is consistent with the more itinerant $5 f$ character and strong conduction electron hybridization. Therefore, since this spectrum is more comparable to that for $\mathrm{UF}_{4}$, the $5 f$ electrons appear to be characterized as more localized in $\mathrm{C}^{+}$implanted uranium. $[13,14]$ The broad peak $38 \mathrm{eV}$ above threshold is multiple-scattering resonance.

The $\mathrm{O}_{4,5}$ EELS spectra of $\mathrm{C}^{+}$implanted uranium and U-oxide are compared in Figure 2 along with the derivative spectra (see insets). The EELS spectrum of the carbon-implanted area (red line) exhibits two major peaks consistent with those labeled A and D in the XAS of Fig. 1. In addition, the shoulders on these peaks seem consistent with those labeled B, C, and E in Fig. 1. However, the derivative of the EELS spectrum only exhibits the shoulder labeled "C". The EELS spectrum of the oxidized, un-implanted uranium (blue line) also exhibits the peak at "C" in derivative mode, but the other two shoulders appear less prevalent. The similarity between the XAS and EELS spectra indicates that the electron transitions in EELS are dipole defensible because the $300 \mathrm{kV}$ electron beam energy is much larger than the transition energy. [15,16] At this high incident electron energy only the direct scattering process is of interest.

\section{CONCLUSIONS}

We have shown that X-ray absorption spectroscopy and electron energy loss spectroscopy are complementary analytical techniques and that electron and photon inelastic scattering amplitudes are comparable for $\mathrm{U}$ oxides and carbides. $\mathrm{O}_{4,5}$ multiplet states are evident in both spectra set and suggest that the $5 f$ states have a rather localized character in $\mathrm{C}^{+}$implanted polycrystalline uranium. Results also show that C-implanted zone resists oxidation.

\section{ACKNOWLEDGEMENTS}

This work was performed under the auspices of the U.S. Dept. of Energy by the University of California Lawrence Livermore National Laboratory under Contract No. W-7405-Eng-48.

\section{REFERENCES}

1. T. Fujikawa, S. Takatoh and S. Usami, Jpn. J. Appl. Phys. 27, 348 (1988).

2. T. Fujikawa, S. Takatoh and S. Usami, Jpn. J. Appl. Phys. 28, 1683 (1989).

3. T. Yikegaki, N. Yiwata, T. Fujikawa and S. Usami, Jpn. J. Appl. Phys. 29, 1362 (1990).

4. A. P. Hitchcock, Jpn. J. Appl. Phys. 32, Suppl. 32-2, 176 (1993).

5. R. Arkush, M.H. Mintz and N. Shamir, J. Nucl. Mater. 281, 182 (2000).

6. A. J. Nelson, T. E. Felter, K. J. Wu, C. Evans, J. L. Ferreira, W. J. Siekhaus, and W. McLean, Surf. Sci. 600, 1319 (2006).

7. Z.Y. Wu, G. Ouvard, P. Gressier and C.R. Natoli, Phys. Rev. B55, 10382 (1997).

8. Y. Zhu, A.R. Moodenbaugh, G. Schneider, J.W. Davenport. T. Vogt, Q. Li, G. Gu, D.A.

Fischer and J. Tafto, Phys. Rev. Lett. 88, 247002 (2002).

9. T. C. Rojas, J. C. Sanchez-Lopez, J. M. Greneche, A. Conde and A. Fernandez, J. Mat. Sci. 39, 4877 (2004). 
10. A. Harvey, B. Guo, I. Kennedy, S. Risbud and V. Leppert, J. Phys.: Condens. Matter 18, 2181 (2006).

11. G.L. Powell, Y-12 Plant, Oak Ridge, Tennessee.

12. G.W. McGillivray, D.A. Geeson and R.C. Greenwood, J. Nucl. Mat. 208, 81 (1994).

13. G. Kalkowski, G. Kaindl, W.D. Brewer and W. Krone, Phys. Rev. B35, 2667 (1987).

14. P. van Kampen, Ch. Gerth, M. Martins, P. K. Carroll, J. Hirsch, E. T. Kennedy, O. Meighan, J.-P. Mosnier, P. Zimmermann, and J. T. Costello, Phys. Rev. A61, 062706 (2000).

15. R.F. Egerton, Electron Energy-loss Spectroscopy in the Electron Microscope, second edition (1996 New York, Plenum), p.221.

16. H.R. Moser and G. Wendin, Phys. Rev. B44, 6044 (1991). 